University of Nebraska - Lincoln

DigitalCommons@University of Nebraska - Lincoln

Food and Drug Administration Papers

U.S. Department of Health and Human Services

2017

Monitoring harm perceptions of smokeless tobacco products among U.S. adults: Health Information National Trends Survey 2012, 2014, 2015

Shari P. Feirman

Elisabeth A. Donaldson

Mark Parascandola

Kimberly Snyder

Cindy Tworek

Follow this and additional works at: https://digitalcommons.unl.edu/usfda

Part of the Dietetics and Clinical Nutrition Commons, Health and Medical Administration Commons, Health Services Administration Commons, Pharmaceutical Preparations Commons, and the Pharmacy Administration, Policy and Regulation Commons

This Article is brought to you for free and open access by the U.S. Department of Health and Human Services at DigitalCommons@University of Nebraska - Lincoln. It has been accepted for inclusion in Food and Drug Administration Papers by an authorized administrator of DigitalCommons@University of Nebraska - Lincoln. 


\title{
Monitoring harm perceptions of smokeless tobacco products among U.S. adults: Health Information National Trends Survey 2012, 2014, 2015
}

\author{
Shari P. Feirman ${ }^{\mathrm{a}, *}$, Elisabeth A. Donaldson ${ }^{\mathrm{a}}$, Mark Parascandola ${ }^{\mathrm{b}}$, Kimberly Snyder ${ }^{\mathrm{a}}$, \\ Cindy Tworek ${ }^{\mathrm{a}}$ \\ a Office of Science, Center for Tobacco Products, U.S. Food and Drug Administration, Silver Spring, MD, United States \\ b Tobacco Control Research Branch, Behavioral Research Program, Division of Cancer Control and Population Sciences, National Cancer Institute, Rockville, MD, United \\ States
}

\section{H I G H L I G H T S}

- A majority of adults do not think smokeless tobacco is less harmful than cigarettes.

- Believing smokeless tobacco is not less harmful than cigarettes declined from 2012-2015.

- Perceptions about the harm of smokeless tobacco differed by demographic subgroup.

\section{A R T I C L E I N F O}

\section{Keywords:}

Smokeless tobacco

Tobacco

Population surveillance

Harm perceptions

United States

\begin{abstract}
A B S T R A C T
Introduction: Changes to the U.S. smokeless tobacco landscape in recent years include a change to health warnings on packages, the implementation of bans in some stadiums, and the launch of a federal youth prevention campaign. It is unclear whether such changes have impacted consumer beliefs about smokeless tobacco. This study examines relative harm perceptions of smokeless tobacco compared to cigarettes among adults and assesses changes in smokeless tobacco harm perceptions over time.

Methods: We analyzed data from three cycles $(2012,2014,2015)$ of the Health Information National Trends Survey (HINTS). Using 2015 data, we assessed bivariate associations between smokeless tobacco harm perceptions and tobacco use, beliefs, information seeking, and demographics. Using 2012, 2014, and 2015 data, we assessed whether smokeless tobacco harm perceptions changed over time within demographic groups using chisquare tests. We then used a weighted multinomial logistic regression to assess the association between smokeless tobacco perceptions and survey year, adjusting for covariates.

Results: When asked whether smokeless tobacco products are less harmful than cigarettes, the majority of respondents across cycles said "no." The percent of respondents who selected this response option decreased over time. Findings showed significant differences in relative harm perceptions of smokeless tobacco versus cigarettes for specific demographic subgroups. Among subgroups, these shifts did not occur with a discernible pattern.

Conclusions: Understanding factors associated with perceptions of smokeless tobacco can inform tobacco control efforts. Additional monitoring of these trends may provide researchers with a deeper understanding of how and why smokeless tobacco harm perceptions change.
\end{abstract}

\section{Introduction}

The U.S. smokeless tobacco landscape has changed in recent years. From 2002-2012, self-reported cigarette use declined, while use of smokeless tobacco saw a slight but significant increase (3.5\% in 2002 to $3.7 \%$ in 2012) (Agaku \& Alpert, 2016). In 2009, the U.S. Food and Drug Administration (FDA) gained regulatory authority over the manufacture, distribution and marketing of tobacco products, including smokeless tobacco products such as snuff and chewing tobacco (Public Law 111-31, 2009). Effective in 2010, Congress required manufacturers to display larger warning messages on smokeless tobacco packages (U.S. Food and Drug Administration, 2016), and in 2015, FDA authorized the marketing of eight new smokeless tobacco products, under the premarket tobacco application pathway, which requires FDA to consider the impact of

\footnotetext{
* Corresponding author at: U.S. Food and Drug Administration, Center for Tobacco Products, Building 71, Room G335 10903, New Hampshire Avenue, Silver Spring, MD 20993-0002, United States.

E-mail address: shari.feirman@fda.hhs.gov (S.P. Feirman).
} 
marketing new tobacco products on the population as a whole (Food and Drug Administration, 2015). Several cities have recently banned smokeless tobacco use in baseball stadiums (Municipal Code of Chicago, n.d.; Admin. Code, n.d.; Mun. Code, n.d.; Los Angeles Municipal Code, n.d.). Additionally, in 2016, FDA launched the first federal campaign aimed at preventing smokeless tobacco use among youth living in rural areas (FDA, 2016). These changes have been accompanied by a debate among experts regarding whether smokeless tobacco products offer a "reduced harm" alternative to cigarettes (Hatsukami, Lemmonds, \& Tomar, 2004; Savitz, Meyer, Tanzer, Mirvish, \& Lewin, 2006). Some experts argue that smokeless tobacco use presents reduced health risks compared to cigarette use and, therefore, smokeless tobacco use should be promoted as an alternative to cigarette, while others argue that smokeless tobacco still presents health risks and, therefore, should not be promoted by public health officials (Gartner, Hall, Chapman, \& Freeman, 2007; Hatsukami et al., 2004). The FDA has the authority to determine whether an individual product can be marketed as a modified risk tobacco product based on data submitted for the individual product. To make that determination, the FDA must use a population health perceptive that considers the impact that such a determination would be likely to have, including "the increased or decreased likelihood that existing users of tobacco products will stop using such products" and "the increased or decreased likelihood that those who do not use tobacco products will start using such products." (US Congress, n.d.). To date, FDA has not made a determination that any smokeless tobacco products are modified risk tobacco products. This question of reduced harm alternatives to cigarettes has intensified in recent years with the introduction of e-cigarettes onto the market (Munz, 2016; Carroll, 2016; Hajek, Etter, Benowitz, Eissenberg, \& McRobbie, 2014; Institute of Medicine, 2001; Kozlowski, 2007, 2015; Zeller, 2013). It is unclear whether, in response to these marketing and regulatory changes, consumers have altered their beliefs about harms of smokeless tobacco.

Behavioral theories posit that harm perceptions predict health-related behaviors (Ajzen, 1985; Janz \& Becker, 1984; Rosenstock, Strecher, \& Becker, 1988) and, in the case of cigarette use, empirical evidence supports these theories (Cengelli, O'Loughlin, Lauzon, \& Cornuz, 2012; Wellman, Dugas, Dutczak, et al., 2016). While research on the relationship between harm perceptions and smokeless tobacco use is limited, evidence from three studies suggests that the perception that smokeless tobacco use presents low risk is associated with smokeless tobacco use (Gansky, Ellison, Kavanagh, Isong, \& Walsh, 2009; Kaufman, Mays, Koblitz, \& Portnoy, 2014; Walsh, Ellison, Hilton, Chesney, \& Ernster, 2000) (consistent with findings on risk perceptions among cigarette smokers (Slovic, 2001)). Additionally, research suggests that cigarette smokers are interested in using "reduced harm" tobacco products (Berg, Haardoerfer, Escoffery, Zheng, \& Kegler, 2015; Parascandola, Augustson, O'Connell, \& Marcus, 2009). Given the harms associated with smokeless tobacco use (U.S. Department of Health and Human Services, 2014; World Health Organization International Agency for Research on Cancer, 2007), it is important to further study smokeless tobacco perceptions.

Previous national surveys of U.S. adults, fielded between 2002 (O'Connor, Hyland, Giovino, Fong, \& Cummings, 2005) to 2013 (Kaufman et al., 2014; Kiviniemi \& Kozlowski, 2015), have found that less than a quarter of respondents believe smokeless tobacco is less harmful than cigarettes (Kaufman et al., 2014; Kiviniemi \& Kozlowski, 2015; O'Connor et al., 2005, 2007; Popova \& Ling, 2013; Regan, Dube, \& Arrazola, 2012). To our knowledge, few national adult surveys have assessed correlates of relative harm perceptions of smokeless tobacco compared to cigarettes. A 2013 survey found that adults who perceived snus to be less harmful and addictive than cigarettes were more likely to have used snus compared to respondents who believed snus was at least as harmful and addictive as cigarettes (Kaufman et al., 2014). A 2012-2013 survey of U.S. adults found no differences in relative harm perceptions of smokeless tobacco compared to cigarettes by smoking status (Kiviniemi \& Kozlowski, 2015). The 2003 International Tobacco Control Policy Four-Country Survey, fielded among U.S. adult cigarette smokers, found that men, younger adults, and those who reported thinking about the harms of smoking recently were likely to believe smokeless tobacco was less harmful than smoking (O'Connor et al., 2005).

The current study examined relative harm perceptions of smokeless tobacco compared to traditional cigarettes in a nationally representative sample of U.S. adults, differences in perceptions by demographic characteristics and other factors (addiction beliefs, cancer beliefs and information seeking behaviors), and whether the prevalence of harm perceptions differs across three time points among the overall sample and subgroups. We looked at differences in perceptions by subgroup because previous research has shown that harm perceptions of smokeless tobacco differ by demographic and tobacco use subgroups (O'Connor et al., 2005). By increasing our understanding of the public's perceptions about these products and how perceptions are have changed in recent years, our findings may help inform public health communications aimed at reducing tobacco-related harms. Additionally, understanding consumer perceptions of tobacco products plays an important role in FDA's regulatory work. For example, FDA has published draft guidance (U.S. Food and Drug Administration, n.d.) explaining the usefulness of data on consumer perceptions of tobacco products in informing FDA decision-making related to the marketing of modified risk tobacco products which, when finalized, will represent the agency's current thinking on this issue.

\section{Methods}

\subsection{Data}

Data were drawn from three cycles of the Health Information National Trends Survey (HINTS). HINTS is a nationally representative, cross-sectional, mail-based survey of civilian, non-institutionalized adults aged $18+$. HINTS data are publicly available (National Cancer Institute, n.d.). We used data from HINTS 4 Cycle 2 collected October 2012-January 2013 with a $40 \%$ response rate $(\mathrm{N}=3,630)$; HINTS 4 Cycle 4 data collected August-November 2014 with a $34 \%$ response rate ( $N=3,677)$; and the 2015 cycle, referred to as HINTS-FDA 2015, collected May-September 2015 with a 33\% response rate $(\mathrm{N}=3,738)$. Methods for HINTS-FDA 2015 are described elsewhere (Blake, Portnoy, Kaufman, et al., in press). All cycles were approved by the Office of Management and Budget and deemed exempt by the National Institute of Health Office of Human Subjects Research.

\subsection{Measures}

All three HINTS cycles included harm perceptions and demographic measures. Use of cigarettes, cigars, and smokeless tobacco; addiction beliefs; and information seeking were only measured in 2015. While the cancer belief construct was measured in all three cycles, the questions used to measure this construct changed in 2015; thus, we included cancer beliefs only in the analysis of 2015 data.

\subsubsection{Harm perceptions}

The primary dependent variable was relative harm perceptions of smokeless tobacco use compared to cigarette smoking. Respondents were asked, "In your opinion, do you think that some smokeless tobacco products, such as chewing tobacco, snus and snuff are less harmful to a person's health than cigarettes?" Response options were "Yes," "No," and "Don't know."

\subsubsection{Use of cigarettes, cigars, and smokeless tobacco}

Respondents were asked if they had smoked at least 100 cigarettes in their lifetime and if they now use cigarettes "Every day," "Some days," or "Not at all." Items assessed the number of cigars, cigarillos, or little filtered cigars smoked in the respondent's lifetime and current use. Respondents were asked if they had used chewing tobacco, snus, snuff, or dip at least 20 times in their lifetime and if they currently use 
Table 1

Factors associated with the belief that smokeless tobacco use is less harmful than cigarettes: HINTS-FDA 2015.

\begin{tabular}{|c|c|c|c|c|c|}
\hline & $\begin{array}{l}\text { Overall n (weighted } \\
\%)\end{array}$ & $\begin{array}{l}\text { Yes, SLT less } \\
\text { harmful } \\
\text { Weighted \% (95\% } \\
\text { CI) }\end{array}$ & $\begin{array}{l}\text { No, SLT not less } \\
\text { harmful } \\
\text { Weighted \% }(95 \% \\
\text { CI) }\end{array}$ & $\begin{array}{l}\text { Don't Know if SLT less } \\
\text { harmful } \\
\text { Weighted \% }(95 \% \mathrm{CI})\end{array}$ & p-Value \\
\hline Overall & 3,738 & $10.9(9.4,12.8)$ & $66.8(63.9,69.6)$ & $22.2(20.0,24.7)$ & $p=0.001$ \\
\hline \multicolumn{6}{|l|}{ Sex } \\
\hline Male & $1,497(46.5)$ & $13.7(11.0,16.8)$ & $65.3(60.7,69.5)$ & $21.1(17.6,25.1)$ & \multirow[t]{2}{*}{$p=0.02$} \\
\hline Female & $2,018(48.2)$ & $8.7(6.8,11.2)$ & $69.5(65.9,72.8)$ & $21.8(18.9,25.0)$ & \\
\hline \multicolumn{6}{|l|}{ Age (years) } \\
\hline $18-34$ & $455(29.5)$ & $9.5(5.7,15.3)$ & $72.6(65.4,78.8)$ & $17.9(12.4,25.3)$ & \multirow[t]{4}{*}{$\mathrm{p}=0.06$} \\
\hline $35-49$ & $659(24.3)$ & $13.4(9.4,18.8)$ & $63.7(58.5,68.7)$ & $22.8(18.2,28.2)$ & \\
\hline $50-64$ & $1,226(24.9)$ & $11.8(9.7,14.2)$ & $68.3(64.4,71.9)$ & $20.0(16.6,23.8)$ & \\
\hline $65+$ & $1,288(18.4)$ & $10.0(8.3,12.1)$ & $60.4(56.6,64.0)$ & $29.6(26.2,33.2)$ & \\
\hline \multicolumn{6}{|l|}{ Race/ethnicity } \\
\hline White, Not Hispanic & $2,633(59.6)$ & $10.5(8.6,12.9)$ & $73.5(70.4,76.4)$ & $15.9(14.1,17.9)$ & \multirow[t]{4}{*}{$p=0.00$} \\
\hline Black, Not Hispanic & $232(10.4)$ & $10.0^{g}(4.4,21.3)$ & $63.0(51.4,73.3)$ & $26.9(18.1,38.1)$ & \\
\hline Hispanic & $517(20.6)$ & $11.4(7.7,16.6)$ & $53.2(46.6,59.6)$ & $35.4(29.7,41.5)$ & \\
\hline Multiple races or other & $312(8.5)$ & $13.8(8.4,21.8)$ & $57.9(46.5,68.6)$ & $28.3(19.6,38.9)$ & \\
\hline \multicolumn{6}{|l|}{ Education } \\
\hline Less than high school & $237(10.7)$ & $8.2^{g}(4.1,15.6)$ & $58.9(48.2,68.7)$ & $32.9(23.9,43.3)$ & \multirow{4}{*}{$p=0.04$} \\
\hline High school graduate & $727(20.7)$ & $9.0(5.4,14.5)$ & $66.1(57.9,73.4)$ & $24.9(19.4,31.4)$ & \\
\hline Vocational or some college & $1,132(32.3)$ & $10.4(7.2,14.9)$ & $70.7(64.9,75.9)$ & $18.8(14.9,23.4)$ & \\
\hline College graduate or postgraduate & $1,578(34.7)$ & $13.8(11.5,16.4)$ & $66.1(61.9,70.1)$ & $20.1(16.5,24.2)$ & \\
\hline \multicolumn{6}{|l|}{ Household income } \\
\hline$<\$ 35,000$ & $1,170(32.1)$ & $10.5(7.1,15.2)$ & $61.0(55.3,66.3)$ & $28.5(24.1,33.4)$ & \multirow[t]{3}{*}{$p=0.0004$} \\
\hline$\$ 35,000$ to $\$ 74,999$ & $1,020(27.0)$ & $8.9(6.9,11.4)$ & $73.0(69.0,76.6)$ & $18.1(14.7,22.0)$ & \\
\hline$\$ 75,000$ or more & $1,112(32.2)$ & $13.2(10.4,16.6)$ & $70.1(64.9,74.9)$ & $16.7(13.3,20.7)$ & \\
\hline \multicolumn{6}{|l|}{ Current tobacco use ${ }^{a}$} \\
\hline Yes & $616(18.2)$ & $13.0(9.4,17.8)$ & $67.7(62.6,72.5)$ & $19.2(14.4,25.3)$ & $\mathrm{p}=0.37$ \\
\hline No & $3,067(80.6)$ & $10.6(8.6,12.9)$ & $66.6(63.2,69.8)$ & $22.8(20.2,25.7)$ & \\
\hline Smokeless tobacco use $\mathrm{b}^{\mathrm{b}}$ & & & & & \\
\hline Ever use & $327(9.4)$ & $23.6(15.8,33.6)$ & $68.6(59.1,76.7)$ & $7.8(5.0,12.0)$ & $\mathrm{p}=\mathbf{0 . 0 0 0}$ \\
\hline Never use & $3,347(88.5)$ & $9.7(8.0,11.7)$ & $66.8(63.7,69.7)$ & $23.5(21.1,26.1)$ & \\
\hline Residence type ${ }^{c}$ & & & & & \\
\hline Urban county & $3,648(98.3)$ & $10.9(9.2,12.8)$ & $66.7(63.7,69.6)$ & $22.4(20.0,24.9)$ & $\mathrm{p}=0.38$ \\
\hline Rural county & $90(1.7)$ & $13.9^{g}(5.8,30.0)$ & $72.6(54.6,85.4)$ & $13.4^{g}(6.1,26.9)$ & \\
\hline Census division & & & & & \\
\hline New England & $163(5.5)$ & $6.4^{g}(3.2,12.3)$ & $73.6(59.1,84.4)$ & $19.9(11.1,33.1)$ & $\mathrm{p}=0.18$ \\
\hline Middle Atlantic & $444(12.5)$ & $10.1(7.1,14.1)$ & $61.1(54.1,67.7)$ & $28.8(23.1,35.2)$ & \\
\hline East North Central & $783(14.7)$ & $9.0(6.3,12.7)$ & $70.2(63.8,75.9)$ & $20.8(15.5,27.3)$ & \\
\hline West North Central & $322(6.5)$ & $14.8(9.5,22.4)$ & $66.6(54.9,76.5)$ & $18.6(9.9,32.2)$ & \\
\hline South Atlantic & $708(21.4)$ & $12.8(8.3,19.2)$ & $64.6(58.7,70.0)$ & $22.6(18.0,27.9)$ & \\
\hline East South Central & $316(6.1)$ & $6.7(4.2,10.7)$ & $78.8(70.7,85.2)$ & $14.4(8.9,22.6)$ & \\
\hline West South Central & 367 (9.9) & $9.4(6.1,14.1)$ & $67.9(59.6,75.3)$ & $22.6(15.8,31.3)$ & \\
\hline Mountain & $242(7.0)$ & $14.0^{g}(6.5,27.6)$ & $71.2(59.8,80.4)$ & $14.8(9.6,22.2)$ & \\
\hline Pacific & $393(16.4)$ & $12.1(7.8,18.2)$ & $61.7(52.8,69.9)$ & $26.2(19.2,34.6)$ & \\
\hline Census region & & & & & \\
\hline Northeast & $607(18.0)$ & $8.9(6.8,11.8)$ & $64.9(58.7,70.7)$ & $26.1(20.8,32.1)$ & $\mathrm{p}=0.53$ \\
\hline Midwest & $1,105(21.2)$ & $10.8(8.4,13.9)$ & $69.1(63.7,74.0)$ & $20.1(15.7,25.3)$ & \\
\hline South & $1,391(37.4)$ & $10.9(8.1,14.5)$ & $67.8(64.3,71.2)$ & $21.3(18.0,24.9)$ & \\
\hline West & $635(23.4)$ & $12.7(8.7,18.1)$ & $64.6(57.2,71.2)$ & $22.8(17.9,28.5)$ & \\
\hline Addiction beliefs about smokeless tobacco ${ }^{\mathrm{d}}$ & & & & & \\
\hline Very addictive & $111(40.5)$ & $9.6(7.6,12.2)$ & $77.9(72.9,82.2)$ & $12.4(9.0,16.9)$ & $\mathrm{p}=\mathbf{0 . 0 0 0}$ \\
\hline Moderately addictive & $674(20.1)$ & $18.7(13.8,24.8)$ & $69.0(62.2,75.1)$ & $12.3(8.4,17.6)$ & \\
\hline Not at all addictive & $1,512(4.3)$ & $10.1(5.6,17.3)$ & $66.4(48.8,80.4)$ & $23.6^{g}(10.7,44.1)$ & \\
\hline Don't know & $1,251(30.1)$ & $7.4(5.6,9.7)$ & $53.5(49.1,57.9)$ & $39.0(34.8,43.5)$ & \\
\hline Information seeking ${ }^{\mathrm{e}}$ & & & & & \\
\hline Health effects (\% Yes) & $648(20.3)$ & $12.9(8.7,13.0)$ & $67.0(59.9,73.4)$ & $20.1(14.6,26.9)$ & $\mathrm{p}=0.61$ \\
\hline $\begin{array}{l}\text { Products that claim to reduce exposure to certain chemicals or } \\
\text { present less risk of disease (\% Yes) }\end{array}$ & $175(5.4)$ & $13.0(7.5,21.7)$ & $69.1(55.8,79.8)$ & $17.9(9.6,30.9)$ & $\mathrm{p}=0.73$ \\
\hline Quitting help/information (\% Yes) & $458(12.7)$ & $15.4(10.2,22.5)$ & $71.0(62.8,78.1)$ & $13.6(8.7,20.7)$ & $\mathrm{p}=\mathbf{0 . 0 3}$ \\
\hline List of chemicals in tobacco products (\% Yes) & $281(9.5)$ & $12.8(7.9,20.0)$ & $76.5(67.9,83.4)$ & $10.7(6.4,17.2)$ & $\mathrm{p}=\mathbf{0 . 0 1}$ \\
\hline Cost/Coupons (\% Yes) & $321(9.9)$ & $12.1(7.9,17.9)$ & $71.5(63.0,78.6)$ & $16.5(11.2,23.6)$ & $\mathrm{p}=0.38$ \\
\hline $\begin{array}{l}\text { Instructions/tutorials } \\
\quad(\% \text { Yes) }\end{array}$ & $37(1.0)$ & $\mathrm{NA}^{\mathrm{h}}$ & $\mathrm{NA}^{\mathrm{h}}$ & $\mathrm{NA}^{\mathrm{h}}$ & $\mathrm{p}=0.92$ \\
\hline Where to buy (\% Yes) & $104(2.9)$ & $21.5^{g}(11.2,37.2)$ & $64.8(49.9,77.4)$ & $13.7(7.9,22.5)$ & $\mathrm{p}=0.04$ \\
\hline Information about new kinds of tobacco products (\% Yes) & $81(2.5)$ & $16.5^{\mathrm{g}}(8.4,29.7)$ & $72.0(55.5,81.2)$ & $11.5(5.4,22.7)$ & $\mathrm{p}=0.15$ \\
\hline Never looked for any of this information (\% Yes) & $2,514(64.4)$ & $10.3(8.2,12.8)$ & $68.4(64.7,71.9)$ & $21.3(18.4,24.5)$ & $\mathrm{p}=0.49$ \\
\hline Other & $96(2.6)$ & $6.8^{g}(2.7,16.0)$ & $54.4(35.7,71.9)$ & $38.8(21.2,59.8)$ & $\mathrm{p}=0.03$ \\
\hline Cancer beliefs $\mathrm{s}^{\mathrm{f}}$ & & & & & \\
\hline Person's behavior/lifestyle causes cancer & & & & & \\
\hline Strongly agree & $285(9.3)$ & $16.9(10.7,25.8)$ & $56.3(45.9,66.2)$ & $26.7(18.5,36.9)$ & $\mathrm{p}=\mathbf{0 . 0 2}$ \\
\hline Somewhat agree & $1,605(40.5)$ & $11.0(8.7,13.9)$ & $69.7(65.2,73.7)$ & $19.3(15.8,23.3)$ & \\
\hline Somewhat disagree & $856(23.0)$ & $10.9(7.3,15.8)$ & $71.4(65.3,76.9)$ & $17.7(14.6,21.2)$ & \\
\hline Strongly disagree & $880(24.9)$ & $8.9(5.9,13.2)$ & $64.2(58.3,69.8)$ & $26.8(21.9,32.4)$ & \\
\hline
\end{tabular}




\begin{tabular}{|c|c|c|c|c|c|}
\hline & $\begin{array}{l}\text { Overall n (weighted } \\
\%)\end{array}$ & $\begin{array}{l}\text { Yes, SLT less } \\
\text { harmful } \\
\text { Weighted \% (95\% } \\
\text { CI) }\end{array}$ & $\begin{array}{l}\text { No, SLT not less } \\
\text { harmful } \\
\text { Weighted \% (95\% } \\
\text { CI) }\end{array}$ & $\begin{array}{l}\text { Don't Know if SLT less } \\
\text { harmful } \\
\text { Weighted \% }(95 \% \mathrm{CI})\end{array}$ & p-Value \\
\hline \multicolumn{6}{|l|}{ Everything causes cancer } \\
\hline Strongly agree & $582(16.6)$ & $10.5(6.8,15.6)$ & $70.9(63.2,77.5)$ & $18.6(13.4,25.3)$ & $\mathrm{p}=\mathbf{0 . 0 3}$ \\
\hline Somewhat agree & $1,406(37.4)$ & $10.7(8.3,13.8)$ & $70.7(66.4,74.7)$ & $18.5(15.7,21.7)$ & \\
\hline Somewhat disagree & $849(22.4)$ & $10.0(7.8,12.8)$ & $69.0(63.1,74.3)$ & $21.0(16.0,27.1)$ & \\
\hline Strongly disagree & $767(20.3)$ & $13.4(8.6,20.2)$ & $57.4(50.6,63.9)$ & $29.2(23.2,36.0)$ & \\
\hline \multicolumn{6}{|c|}{ Cancer prevention is not possible } \\
\hline Strongly agree & $211(7.3)$ & $15.7^{g}(6.3,33.9)$ & $52.2(39.7,64.5)$ & $32.1(19.9,47.3)$ & $\mathrm{p}=0.06$ \\
\hline Somewhat agree & $689(18.4)$ & $8.4(6.1,11.6)$ & $66.6(60.0,72.6)$ & $24.9(19.3,31.6)$ & \\
\hline Somewhat disagree & $1,497(41.0)$ & $9.6(7.5,12.1)$ & $70.1(65.5,74.4)$ & $20.3(19.9,24.2)$ & \\
\hline Strongly disagree & $1,217(30.4)$ & $13.5(10.2,17.7)$ & $68.1(64.6,70.2)$ & $18.4(19.3,23.9)$ & \\
\hline \multicolumn{6}{|c|}{ Cancer prevention recommendations are hard to follow } \\
\hline Strongly agree & $1,191(31.3)$ & $9.1(6.8,12.1)$ & $68.6(63.8,73.0)$ & $22.2(18.7,26.3)$ & $\mathrm{p}=0.66$ \\
\hline Somewhat agree & $1,619(42.4)$ & $11.7(9.3,14.7)$ & $66.6(63.0,70.1)$ & $21.6(18.8,24.8)$ & \\
\hline Somewhat disagree & $526(14.8)$ & $10.8(8.2,13.9)$ & $69.1(61.5,75.8)$ & $20.1(14.8,26.7)$ & \\
\hline Strongly disagree & $308(9.5)$ & $13.9^{g}(6.8,26.2)$ & $61.2(46.7,73.9)$ & $24.9(16.4,35.9)$ & \\
\hline
\end{tabular}

Boldface indicates statistical significance $(\mathrm{p}<0.05$ ).

Abbreviations: CI - confidence interval.

${ }^{\text {a }}$ Current tobacco use is defined as smoking at least 100 cigarettes, 50 cigars, or use of 20 smokeless products in a lifetime and now using cigarettes, cigars, and/or smokeless products some or every day.

${ }^{b}$ Ever use of smokeless tobacco is defined as using chewing tobacco, snus, snuff, or dip at least 20 times in a lifetime.

c An urban county was a county in a metro area or a non-metro county with a population size greater than 2,500. A rural county is a non-metro county that is completely rural or less than 2,500 in population size.

d Respondents were asked about how addictive they believed smokeless tobacco use is with response options as follows: "Not at all addictive," Moderately addictive," "Very addictive," and "Don't know."

e Information seeking was assessed by asking respondents "Have you ever looked for any of the following information about tobacco products (e.g. cigarettes, cigars, or chewing tobacco) from any source?" Respondents were able to select all response options that applied. The proportion responding "Yes" to each of the response options is presented.

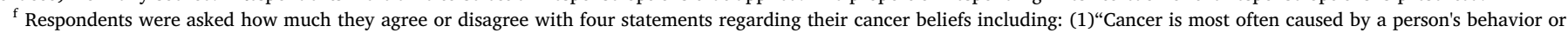

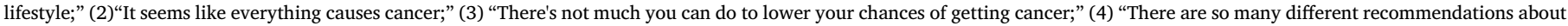
preventing cancer, it's hard to know which ones to follow.

${ }^{g}$ Estimates are flagged because the relative standard error is greater than $30 \%$.

${ }^{\mathrm{h}}$ Estimates are suppressed because the denominator is less than 50 .

smokeless products. Current use of a tobacco product was defined as having used at least 100 cigarettes, 50 or more cigars, or 20 smokeless tobacco products in a lifetime and currently using cigarettes, cigars, and/or smokeless tobacco products some days or every day, consistent with previous research (Hu, Neff, Agaku, et al., 2016). We defined ever smokeless tobacco use as respondents who had used chewing tobacco, snus, snuff, or dip at least 20 times in their lifetime.

\subsubsection{Addiction beliefs}

Respondents were asked: "How addictive do you believe the following is: smokeless tobacco use." Response options were "Not at all addictive," "Moderately addictive," "Very addictive," and "Don't know."

\subsubsection{Information seeking}

Respondents were asked: "Have you ever looked for any of the following information about tobacco products (i.e., cigarettes, cigars, or chewing tobacco) from any source?" Respondents could select all applicable responses: health effects, products that claim to reduce exposure to certain chemicals or present less risk of disease, quitting help/ information, list of chemicals in tobacco products, cost/coupons, instructions/tutorials, where to buy, information about new kinds of tobacco products, something else.

\subsubsection{Cancer beliefs}

Respondents were given four statements: (Agaku \& Alpert, 2016) "Cancer is most often caused by a person's behavior or lifestyle;" (Public Law 111-31, 2009) "It seems like everything causes cancer;" (U.S. Food and Drug Administration, 2016) "There's not much you can do to lower your chances of getting cancer;" (Food and Drug Administration, 2015) "There are so many different recommendations about preventing cancer, it's hard to know which ones to follow." Response options were:
"Strongly Agree," "Somewhat Agree," "Somewhat Disagree," "Strongly Disagree."

\subsubsection{Demographic variables}

Our analysis included: rural/urban residence, gender, education, annual household income, and race/ethnicity. Rural/urban residence was categorized based on respondent address for census region, division, and residence in an urban or rural area. Urban/rural county residence was based on the 2003 US Department of Agriculture's rural/ urban designation (USDA Economic Research Service, n.d.). Urban counties were counties in metro areas or non-metro counties with population sizes greater than 2,500. Rural counties were non-metro counties that were completely rural or less than 2,500 in population size.

\subsection{Statistical Analysis}

Data were analyzed in 2016. Stata 14 with survey procedures was used for this analysis (StataCorp, 2015). To account for the complex sampling design and to generate nationally representative estimates at each time point, all analyses incorporated jackknife replicate weights. With 2015 data, we conducted chi-square tests to examine bivariate associations between smokeless tobacco harm perceptions and tobacco use, beliefs, information seeking and demographic characteristics. With 2012, 2014, and 2015 data, we conducted chi-square tests to assess whether smokeless tobacco harm perceptions changed over time within each demographic subgroup. Using 2012, 2014, and 2015 data, we used a weighted multinomial logistic regression to examine the association between smokeless tobacco harm perceptions and survey year, adjusting for demographic variables including gender, age, race/ethnicity, household income, education, and rural/urban residence. Respondents selecting "no" (smokeless tobacco is not less harmful than cigarettes) 
were the reference group. We estimated odds ratios for 1) respondents reporting "yes" (smokeless tobacco is less harmful than cigarettes) versus "no," and 2) respondents reporting "don't know" versus "no." Estimates with denominators less than 50 were suppressed and those with a relative standard error greater than $30 \%$ were noted, as they may be unreliable and should be interpreted with caution.

\section{Results}

Weighted proportions of the relative harm perceptions of smokeless tobacco compared to cigarettes in 2015, by demographic, tobacco use and belief characteristics are displayed in Table 1. When asked whether some smokeless tobacco products "are less harmful to a person's health than cigarettes," the majority of respondents $(66.8 \%, 95 \% \mathrm{CI}=63.9$, 69.6) said "no," $22.2 \%(95 \% \mathrm{CI}=20.0,24.7)$ said "don't know," and $10.9 \%(95 \% \mathrm{CI}=9.4,12.8)$ said "yes." Chi-squared tests revealed significant differences in harm perceptions by gender, race/ethnicity, education, household income, smokeless tobacco use, addiction beliefs, certain information seeking behaviors, and certain cancer beliefs. In general, male gender, higher education or income, and tobacco use was associated with a greater likelihood of believing that SLT is less harmful than cigarettes. Regarding cancer beliefs, the belief everything causes cancer was significantly associated with relative smokeless tobacco harm perceptions, as was the belief that cancer is most often caused by a person's behavior or lifestyle. However, the pattern was unclear for the belief that cancer prevention is not possible and the belief that cancer prevention recommendations are hard to follow. Regarding information seeking behaviors, significant differences in harm perceptions were observed for respondents reporting that they had ever looked for information about quitting help/information, chemicals in tobacco products, and where to buy tobacco products.

Table 2 presents changes in relative harm perceptions of smokeless tobacco compared to cigarettes in 2012, 2014 and 2015. Across the cycles, the majority of respondents believed that smokeless tobacco was not less harmful than cigarettes. There were significant differences in relative harm perceptions of smokeless tobacco compared to cigarettes across cycles for the overall population $(p=0.0001)$. The percent of respondents who did not believe smokeless tobacco was less harmful than cigarettes decreased over time $(73.5 \%$ in $2012,72.1 \%$ in 2014 , and $66.8 \%$ in 2015).

While we observed significant differences in smokeless tobacco harm perceptions across cycles for demographic subgroups (Table 2), we did not observe an overarching consistent pattern in how these perceptions changed. For instance, the belief that some smokeless tobacco products were less harmful than cigarettes was higher for women in 2015 compared to 2012, but the percent of women endorsing this belief peaked in 2014. Similar non-linear patterns were seen for respondents who were older (ages 50-64 years and 65 + years); nonHispanic Black adults; those with low income $(<\$ 35,000)$; and those living in non-rural counties. Other subgroups exhibited different patterns in relative harm perceptions across cycles. For example, the percent of 35-39 year-olds who believed some SLT products were less harmful than cigarettes was lowest in 2014, while the percent of males and college graduates reporting this belief increased from 2012 to 2014, and from 2014 to 2015. Of note, respondents answering "don't know" to the harm perceptions question fluctuated across cycles for several subgroups. For example, the percent of men responding "don't know" to this question was $17.0 \%(95 \% \mathrm{CI}=13.5,21.3)$ in 2012 , $14.1 \%(95 \% \mathrm{CI}=11.3,17.5)$ in 2014 , and $21.1 \%(95 \% \mathrm{CI}=17.6$, 25.0) in 2015.

Table 3 presents changes in harm perceptions of smokeless tobacco compared to cigarettes over time, controlling for demographic covariates. When asked whether some smokeless tobacco products are less harmful than cigarettes, the odds of saying "don't know" versus "no" was significantly higher in 2015 compared to 2012 (OR $=1.41$, 95\% $\mathrm{CI}=1.08,1.84)$. There were also significant differences by demographic characteristics. The odds of believing that smokeless tobacco is less harmful than cigarettes, compared to not holding that belief, was significantly lower for women versus men (OR $=0.74,95 \%$ $\mathrm{CI}=0.58,0.95)$. Compared to non-Hispanic White adults, other racial/ ethnic subgroups had more than two times the odds of reporting "don't know" versus "no" when asked whether some smokeless tobacco products are less harmful than cigarettes $(\mathrm{OR}=2.72,95 \% \mathrm{CI}=2.12$, 3.48 ) for Hispanics; $\mathrm{OR}=2.75,95 \% \mathrm{CI}=1.85,4.08$ ) for other racial/ ethnic groups). Those with higher household incomes were significantly less likely to report "don't know" versus "no," compared to those with an annual household income of less than $\$ 35,000 \quad\left(\mathrm{OR}_{\$ 35,000-}\right.$ $\$ 74,999=0.71, \quad 95 \% \quad \mathrm{CI}=0.55, \quad 0.91 ; \quad \mathrm{OR}_{\$ 75,000+}=0.72, \quad 95 \%$ $\mathrm{CI}=0.53,0.97)$

\section{Discussion}

We examined factors associated with relative harm perceptions of smokeless tobacco compared to cigarettes. Across the three HINTS cycles, a majority of respondents reported that they did not think some smokeless tobacco products were less harmful than cigarettes. The percent of respondents with this belief decreased over time. After controlling for demographic covariates, relative harm perceptions of smokeless tobacco significantly changed between 2012 and 2015 for the US population and within demographic subgroups.

While we did not observe overarching patterns of change that were consistent among the full population or specific subgroups over time, our findings elucidate the complexity of understanding relative harm perceptions of smokeless tobacco. For example, we explored factors that we believed might be associated with smokeless tobacco harm perceptions from a theoretical perspective, such as cancer beliefs and information seeking behaviors. Results from the bivariate analyses seemed to show inconsistent results, whereby the belief everything causes cancer was significantly associated with the outcome of interest, but the belief that cancer prevention is not possible showed no significant association. These two constructs may not be as closely related as they appear to be. Additionally, certain information seeking behaviors were significantly associated with relative harm perceptions of smokeless tobacco, while others were not; there did not seem to be common characteristics between significant versus non-significant behaviors. It could be that these constructs are not associated with smokeless tobacco harm perceptions or that this survey did not adequately measure those constructs.

It is unclear why consumers maintain or change their smokeless tobacco harm perceptions over time. Possibly, as more products are introduced onto the marketplace, such as e-cigarettes, consumers are prompted to reconsider their perceptions of existing products. It is also possible that, in this new environment in which conflicting messages about the harms of e-cigarettes are communicated in media (Tavernise, n.d.; Wall Street Journal, n.d.; Clarke, n.d.), answering questions about tobacco-related harms may require respondents to exert more cognitive effort than it previously did. This may explain the shift seen (Krosnick, 1991), whereby the percent of respondents answering "don't know" to the relative harm perception question increased over time. Similar to previous research, our analysis found that being non-White was associated with selecting "don't know" in response to the risk perception question (Waters, Hay, Orom, Kiviniemi, \& Drake, 2013). We were unable to identify another question with a "don't know" response that was asked in all three HINTS survey years (2012, 2014, and 2015). Thus, we cannot know whether "don't know" responses would have increased for other questions over time, or whether this phenomenon is unique to the harm perceptions question. Variations in the amount of tobacco advertising to which consumers have been exposed around the time surveys were fielded could also explain changes in smokeless tobacco perceptions across cycles. E-cigarette advertising has increased in recent years (Cantrell, Emelle, Ganz, Hair, \& Vallone, 2016; Kim, Arnold, \& Makarenko, 2014; Kornfield, Huang, Vera, \& Emery, 2015); 


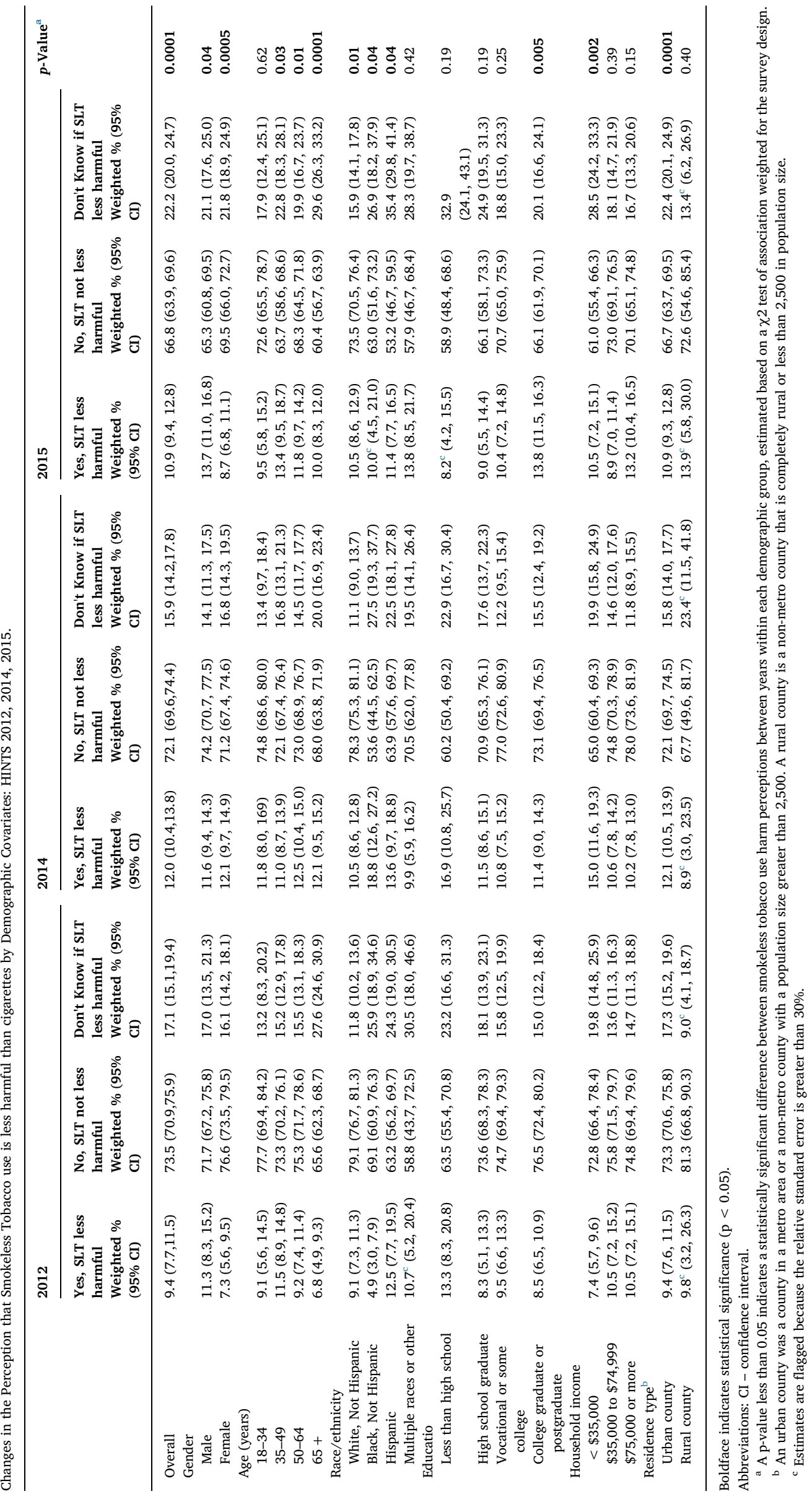


Table 3

Factors associated with changes in harm perceptions of smokeless tobacco between 2012, 2014 and 2015, controlling for demographic characteristics.

\begin{tabular}{|c|c|c|c|c|}
\hline & $\begin{array}{l}\text { Yes (vs No) }{ }^{\mathrm{a}} \\
\text { OR }(95 \% \mathrm{CI})\end{array}$ & $p$-Value & $\begin{array}{l}\text { Don't Know (vs No) } \\
\text { OR }(95 \% \mathrm{CI})\end{array}$ & $p$-Value \\
\hline \multicolumn{5}{|l|}{ Survey year } \\
\hline 2012 & Ref. & & Ref. & \\
\hline 2014 & $1.24(0.91,1.71)$ & 0.17 & $0.95(0.74,1.22)$ & 0.70 \\
\hline 2015 & $1.31(0.96,1.78)$ & 0.09 & $1.41(1.08,1.84)$ & 0.01 \\
\hline \multicolumn{5}{|l|}{ Gender } \\
\hline Male & Ref. & & Ref. & \\
\hline Female & $0.74(0.58,0.95)$ & 0.02 & $0.97(0.80,1.17)$ & 0.74 \\
\hline \multicolumn{5}{|l|}{ Age (years) } \\
\hline $18-34$ & Ref. & & Ref. & \\
\hline $35-49$ & $1.41(0.96,2.05)$ & 0.08 & $1.49(1.08,2.06)$ & 0.02 \\
\hline $50-64$ & $1.19(0.83,1.70)$ & 0.34 & $1.33(0.96,1.83)$ & 0.08 \\
\hline $65+$ & $1.18(0.83,1.67)$ & 0.37 & $2.15(1.58,2.92)$ & 0.000 \\
\hline \multicolumn{5}{|l|}{ Race/ethnicity } \\
\hline White, Not Hispanic & Ref. & & Ref. & \\
\hline Black, Not Hispanic & $1.43(0.90,2.27)$ & 0.12 & $2.75(1.97,3.82)$ & 0.000 \\
\hline Hispanic & $1.53(1.05,2.23)$ & 0.03 & $2.72(2.13,3.48)$ & 0.000 \\
\hline Multiple races or other & $1.54(0.99,2.40)$ & 0.06 & $2.75(1.85,4.08)$ & 0.000 \\
\hline \multicolumn{5}{|l|}{ Education } \\
\hline Less than high school & Ref. & & Ref. & \\
\hline High school graduate & $0.68(0.41,1.26)^{\mathrm{c}}$ & 0.13 & $1.02(0.68,1.51)$ & 0.92 \\
\hline Vocational or some college & $0.77(0.45,1.30)^{\mathrm{c}}$ & 0.32 & $0.91(0.64,1.29)$ & 0.59 \\
\hline College graduate or postgraduate & $0.85(0.51,1.43)^{\mathrm{c}}$ & 0.55 & $1.02(0.69,1.53)$ & 0.91 \\
\hline \multicolumn{5}{|l|}{ Household income } \\
\hline$<\$ 35,000$ & Ref. & & Ref. & \\
\hline$\$ 35,000$ to $\$ 74,999$ & $0.85(0.61,1.19)$ & 0.35 & $0.71(0.55,0.91)$ & 0.01 \\
\hline$\$ 75,000$ or more & $0.94(0.64,1.38)$ & 0.75 & $0.72(0.53,0.97)$ & 0.03 \\
\hline \multicolumn{5}{|l|}{ Residence type ${ }^{b}$} \\
\hline Urban county & Ref. & & Ref. & \\
\hline Rural county & $0.95(0.45,2.00)^{\mathrm{c}}$ & 0.89 & $0.75(0.37,1.51)^{\mathrm{c}}$ & 0.42 \\
\hline
\end{tabular}

Boldface indicates statistical significance $(\mathrm{p}<0.05)$.

${ }^{\text {a }}$ Respondents were asked the following item to assess harm perceptions of smokeless tobacco products relative to cigarettes: "In your opinion, do you think that some smokeless

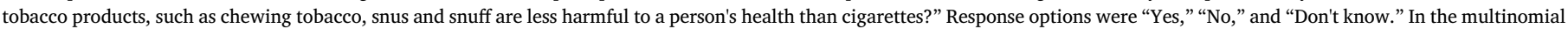

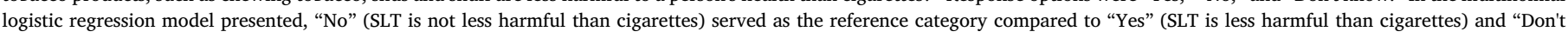
know" (whether SLT is less harmful than cigarettes).

${ }^{\mathrm{b}}$ An urban county was a county in a metro area or a non-metro county with a population size greater than 2,500 . A rural county is a non-metro county that is completely rural or less than 2,500 in population size.

${ }^{\mathrm{c}}$ Estimates are flagged because the relative standard error is greater than $30 \%$.

tobacco industry spending on cigarette advertising/promotion decreased from 2012-2013 (Federal Trade Commission, 2016a); and smokeless tobacco spending increased (Federal Trade Commission, 2016b). The type of tobacco advertising to which consumers are exposed may also influence perceptions (Wackowski, Lewis, \& Delnevo, 2016); research indicates that tobacco industry marketing, framing ecigarettes and hookah as safe, appear to be effective (Berg, Stratton, Schauer, et al., 2015). The extent to which consumers are aware of the harm reduction debates among experts - and the extent to which awareness of such debates impacts consumer harm perceptions - is unclear.

A strength of this study is its nationally representative sample. Also, while previous studies have examined harm perceptions of smokeless tobacco with cross-sectional data from one time point (Gansky et al., 2009; Kaufman et al., 2014; Walsh et al., 2000), this study examines how smokeless tobacco harm perceptions have changed over time.

This study was subject to several limitations. First, we examined cross-sectional data. Longitudinal data may have provided deeper insight into reasons for differences in smokeless tobacco harm perceptions since 2012. Nevertheless, examining responses to the same question assessing smokeless tobacco harm perceptions across three cycles provides a unique snapshot of overarching changes in consumer perceptions over time and is a strength of this study. Second, estimates for certain subpopulations of interest were unstable, which precludes us from making inferences regarding their harm perceptions of smokeless tobacco. For example, most findings for individuals living in rural areas, who have a high prevalence of smokeless tobacco use, were unstable (Rodu \& Cole, 2009; Vander Weg, Cunningham, Howren, \& Cai, 2011).
Third, we did not examine absolute harm perceptions of smokeless tobacco because the question assessing this construct was inconsistent across cycles. Ideally, we would have liked to assess both relative and absolute harm perceptions. There were also other questions of interest in 2015 that were not asked in 2012 or 2014. For example, had the question assessing addiction beliefs been asked in multiple cycles, we would have examined responses to the question over time. Smokeless tobacco use was also only measured in 2015; we could not adjust for changes in use over time. This is a limitation because differences in smokeless tobacco use status could have helped explain some of the changes in smokeless tobacco harm perceptions seen over time.

Understanding factors associated with relative harm perceptions of smokeless tobacco versus cigarettes -in recent surveys and over time can inform tobacco regulatory and prevention efforts. Our findings may inform the development of tailored educational content for specific subgroups. To build upon this study, future research might examine absolute harm perceptions of smokeless tobacco and continue to track changes in relative harm perceptions of smokeless tobacco. Research examining which specific beliefs (e.g. beliefs about cancer or, beliefs about addiction) drive harm perceptions of smokeless tobacco might provide us with a more nuanced understanding of how consumers judge smokeless tobacco products. In addition, focus groups may also provide a deeper understanding of shifts over time in smokeless tobacco harm perceptions.

\section{Conclusions}

We observed significant shifts in relative harm perceptions of 
smokeless tobacco compared to cigarettes over time, although these shifts did not occur with any discernible pattern among demographic subgroups. Additional monitoring of these trends, as well as qualitative data, may provide researchers with a deeper understanding of how and why smokeless tobacco harm perceptions change and help to inform tobacco prevention efforts.

\section{Disclaimer}

The content of this publication does not reflect the views or policies of the Department of Health and Human Services, nor does the mention of trade names, commercial products, or organizations imply endorsement by the U.S. government. The findings and conclusion in this report are those of the authors and do not represent FDA or NIH positions or policies.

\section{Role of funding sources}

Publication of this article was supported by the U.S. Food and Drug Administration, Center for Tobacco Products, and the U.S. National Cancer Institute, National Institutes of Health. No funding was provided specifically for conducting the analysis, drafting the manuscript, or submitting this paper for publication.

\section{Contributors}

SF led the conceptualization of this project, with contributions from all authors. SF and ED planned the statistical analysis, with input from all authors. ED managed the data and conducted the statistical analyses. All authors participated in interpreting the results. SF wrote a preliminary draft of the manuscript. KS contributed to the research for and writing of the Introduction section, and ED contributed to the writing of the Methods section. All authors edited the manuscript for critical intellectual content and approved the final version submitted.

\section{Conflict of interest}

All authors declare that they have no conflicts of interest.

\section{References}

Agaku, I. T., \& Alpert, H. R. (2016). Trends in annual sales and current use of cigarettes, cigars, roll-your-own tobacco, pipes, and smokeless tobacco among US adults, 2002-2012. Tobacco Control, 25(4), 451-457.

Ajzen, I. (1985). From intentions to actions: A theory of planned behavior. Springer.

Berg, C. J., Haardoerfer, R., Escoffery, C., Zheng, P., \& Kegler, M. (2015a). Cigarette users' interest in using or switching to electronic nicotine delivery systems for smokeless tobacco for harm reduction, cessation, or novelty: a cross-sectional survey of US adults. Nicotine \& Tobacco Research, 17(2), 245-255.

Berg, C. J., Stratton, E., Schauer, G. L., et al. (2015b). Perceived harm, addictiveness, and social acceptability of tobacco products and marijuana among young adults: marijuana, hookah, and electronic cigarettes win. Substance Use \& Misuse, 50(1), 79-89.

Blake, K. D., Portnoy, D. B., Kaufman, A. R., et al. (2017). Rationale, procedures, and response rates for the 2015 Administration of NCI's Health Information National Trends Survey: HINTS-FDA 2015. Journal of Health Communication, 21(12), 1269-1275.

Cantrell, J., Emelle, B., Ganz, O., Hair, E. C., \& Vallone, D. (2016). Rapid increase in ecigarette advertising spending as Altria's MarkTen enters the marketplace. Tobacco Control, 25, e16-e18.

Carroll, A. E. (2016). The New York Times. May 10, 2016E-cigarettes are safer, but not exactly safe.

Cengelli, S., O'Loughlin, J., Lauzon, B., \& Cornuz, J. (2012). A systematic review of longitudinal population-based studies on the predictors of smoking cessation in adolescent and young adult smokers. Tobacco Control, 21(3), 355-362.

Clarke, T. E-cigarettes could cut smoking-related deaths by 21 percent: study. Reuters. Published July 14, 2016. Accessed July 15, 2016. http://www.reuters.com/article/ us-health-ecigarettes-study-idUSKCNOZU2IP.

Federal Trade Commission (2016a). Federal Trade Commission Cigarette Report for 2013.

Federal Trade Commission (2016b). Federal Trade Commission Smokeless Tobacco Report for 2013.

FDA News Release: FDA launches first ad campaign focused on dangers of smokeless tobacco among rural teens [press release].

Food and Drug Administration (2015). FDA news release. FDA issues first product marketing orders through premarket tobacco application pathway. November 10, 2015 http://www.fda.gov/NewsEvents/Newsroom/PressAnnouncements/ucm472026. htm? source $=$ govdelivery\&utm_medium $=$ email\&utm_source $=$ govdelivery (press release) .

Gansky, S. A., Ellison, J. A., Kavanagh, C., Isong, U., \& Walsh, M. M. (2009). Patterns and correlates of spit tobacco use among high school males in rural California. Journal of Public Health Dentistry, 69(2), 116-124.

Gartner, C. E., Hall, W. D., Chapman, S., \& Freeman, B. (2007). Should the health community promote smokeless tobacco (snus) as a harm reduction measure? PLoS Medicine, 4(7), e185.

Hajek, P., Etter, J. F., Benowitz, N., Eissenberg, T., \& McRobbie, H. (2014). Electronic cigarettes: review of use, content, safety, effects on smokers and potential for harm and benefit. Addiction, 109(11), 1801-1810.

Hatsukami, D. K., Lemmonds, C., \& Tomar, S. L. (2004). Smokeless tobacco use: harm reduction or induction approach? Preventive Medicine, 38(3), 309-317.

Institute of Medicine (2001). Clearing the smoke: assessing the science base for tobacco harm reduction. Washington: National Academy Press.

Janz, N. K., \& Becker, M. H. (1984). The health belief model: a decade later. Health Education Quarterly, 11(1), 1-47.

Kaufman, A. R., Mays, D., Koblitz, A. R., \& Portnoy, D. B. (2014). Judgments, awareness, and the use of snus among adults in the United States. Nicotine \& Tobacco Research, 16(10), 1404-1408.

Kim, A. E., Arnold, K. Y., \& Makarenko, O. (2014). E-cigarette Advertising Expenditures in the U.S., 2011-2012. American Journal of Preventive Medicine, 46(4), 409-412.

Kiviniemi, M. T., \& Kozlowski, L. T. (2015). Deficiencies in public understanding about tobacco harm reduction: results from a United States national survey. Harm Reduction Journal, 12(1), 1-7.

Kornfield, R., Huang, J., Vera, L., \& Emery, S. L. (2015). Rapidly increasing promotional expenditures for e-cigarettes. Tobacco Control, 24(2), 110-111.

Kozlowski, L. T. (2007). Effect of smokeless tobacco product marketing and use on population harm from tobacco use: Policy perspective for tobacco-risk reduction. American Journal of Preventive Medicine, 33(6), S379-S386.

Kozlowski, L. T. (2015). Prospects for a nicotine-reduction strategy in the cigarette endgame: Alternative tobacco harm reduction scenarios. The International Journal on Drug Policy, 26(6), 543-547.

Krosnick, J. A. (1991). Response strategies for coping with the cognitive demands of attitude measures in surveys. Applied Cognitive Psychology, 5(3), 213-236.

Munz, M. (2016). Young adults say vaping helped them quit smoking, restrictions are Dangerous. St. Louis post-dispatch (Sep 8).

National Cancer Institute. Health information national trends survey. (2005). http://hints. cancer.gov (Accessed July 6, 2016).

O'Connor, R. J., Hyland, A., Giovino, G. A., Fong, G. T., \& Cummings, K. M. (2005). Smoker awareness of and beliefs about supposedly less-harmful tobacco products. American Journal of Preventive Medicine, 29(2), 85-90.

O'Connor, R. J., McNeill, A., Borland, R., Hammond, D., King, B., \& Boudreau, C. (2007), Smokers' beliefs about the relative safety of other tobacco products: findings from the ITC collaboration. Nicotine \& Tobacco Research, 9.

Parascandola, M., Augustson, E., O'Connell, M. E., \& Marcus, S. (2009). Consumer awareness and attitudes related to new potential reduced-exposure tobacco product brands. Nicotine \& Tobacco Research, 11(7), 886-895.

Popova, L., \& Ling, P. M. (2013). Perceptions of relative risk of snus and cigarettes among US smokers. American Journal of Public Health, 103(11), e21-e23.

Prohibition of using smokeless tobacco at sports arenas and recreational areas that issue tickets. (Vol Admin. Code ch. 5, 17-503.1. N.Y., N.Y).

Public Law 111-31 (2009). Family smoking prevention and tobacco control act.

Regan, A. K., Dube, S. R., \& Arrazola, R. (2012). Smokeless and flavored tobacco products in the U.S.: 2009 Styles survey results. American Journal of Preventive Medicine, 42(1), 29-36.

Rodu, B., \& Cole, P. (2009). Smokeless tobacco use among men in the United States, 2000 and 2005. Journal of Oral Pathology \& Medicine, 38(7), 545-550.

Rosenstock, I. M., Strecher, V. J., \& Becker, M. H. (1988). Social learning theory and the Health Belief Model. Health Education Quarterly, 15(2), 175-183.

Savitz, D. A., Meyer, R. E., Tanzer, J. M., Mirvish, S. S., \& Lewin, F. (2006). Public health implications of smokeless tobacco use as a harm reduction strategy. American Journal of Public Health, 96(11), 1934-1939.

Slovic, P. (Ed.). (2001). Smoking: Risk, Perception, Policy. SAGE Publications.

Hu, S. S., Neff, L., Agaku, I. T., et al. (2016). Tobacco product use among adults - United States, 2013-2014. MMWR. Morbidity and Mortality Weekly Report, 65(27), 685-691.

StataCorp (2015). Stata Statistical Software: Release 14. College Station, TX: StataCorp LP.

Tavernise, S. Smokers urged to switch to e-cigarettes by British Medical Group. The New York Times. Published April 27, 2016. Accessed July 15, 2016. http://www.nytimes. com/2016/04/28/health/e-cigarettes-vaping-quitting-smoking-royal-college-ofphysicians.html? $r=0$.

U.S. Department of Health and Human Services (2014). The health consequences of smoking: 50 years of progress. Atlanta, GA: U.S. Department of Health and Human Services, Centers for Disease Control and Prevention, National Center for Chronic Disease Prevention and Health Promotion, Office on Smoking and Health.

U.S. Food and Drug Administration. Smokeless tobacco product warning labels. (2016). Retrieved from http://www.fda.gov/TobaccoProducts/Labeling/Labeling/ ucm2023662.htm (Accessed September 18).

U.S. Food and Drug Administration. Modified risk tobacco product applications: Draft guidance for industry. (2011). March 2012 https://www.fda.gov/downloads/ TobaccoProducts/Labeling/RulesRegulationsGuidance/UCM297751.pdf (Accessed July 31,2017$)$.

US Congress. Federal Food Drug and Cosmetic Act Sec 907, 910, 911—as amended by FSPTCA. (6-22-2009) 
USDA Economic Research Service. Measuring Rurality. https://wayback.archive-it.org/ 5923/20110913224455/http://ers.usda.gov/Briefing/Rurality/ (Accessed July 6, 2016).

Use of smokeless tobacco and other tobacco products prohibited at sites for professional and amateur baseball and other sporting events. (Vol Mun. Code § 7-4.15. Boston, MA2015).

Use of smokeless tobacco at sites for professional and amateur baseball and other sporting events prohibited (Ch 7-32-032). Chicago, IL: Municipal Code of Chicago.

Use of smokeless tobacco prohibited at event sites for organized sporting events. Chapter IV Public Welfare. Vol 41.50.1. Los Angeles Municipal Code.

Vander Weg, M. W., Cunningham, C. L., Howren, M. B., \& Cai, X. (2011). Tobacco use and exposure in rural areas: Findings from the Behavioral Risk Factor Surveillance System. Addictive Behaviors, 36(3), 231-236.

Wackowski, O. A., Lewis, M. J., \& Delnevo, C. D. (2016). Interviews with smokers about smokeless tobacco products, risk messages and news articles. Tobacco Control, 25(6), $671-678$.
Are e-cigarettes a healthy way to quit smoking? Wall Street Journal. April 11, 2016. Accessed July 15, 2016. http://www.wsj.com/articles/are-e-cigarettes-a-healthyway-to-quit-smoking-1460340169.

Walsh, M. M., Ellison, J., Hilton, J. F., Chesney, M., \& Ernster, V. L. (2000). Spit (smokeless) tobacco use by high school baseball athletes in California. Tobacco Control, 9(Suppl. 2), II32-39.

Waters, E. A., Hay, J. L., Orom, H., Kiviniemi, M. T., \& Drake, B. F. (2013). "Don't know" responses to risk perception measures: implications for underserved populations. Medical Decision Making, 33(2), 271-281.

Wellman, R. J., Dugas, E. N., Dutczak, H., et al. (2016). Predictors of the onset of cigarette smoking: a systematic review of longitudinal population-based studies in youth. American Journal of Preventive Medicine, 51(5), 767-778.

World Health Organization International Agency for Research on Cancer (2007). Smokeless tobacco and some tobacco-specific N-nitrosamines (Lyon, France).

Zeller, M. (2013). Reflections on the 'endgame' for tobacco control. Tobacco Control, 22(suppl 1), i40-i41. 